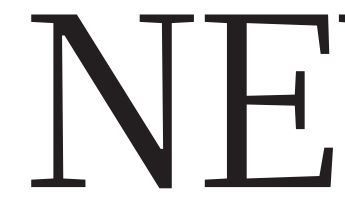

GENE-EDITING Patent dispute over CRISPR tool intensifies p.265
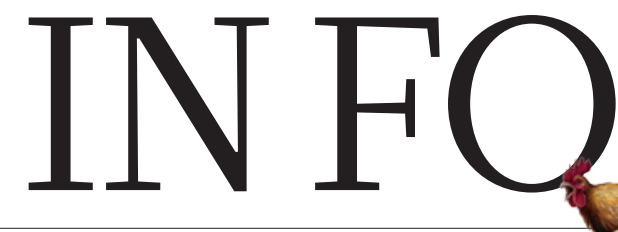

CLIMATE Research blitz aims to unlock secrets of E1 Niño p.267
SPACE Best evidence yet for ninth solar system planet $\mathbf{p . 2 6 6}$

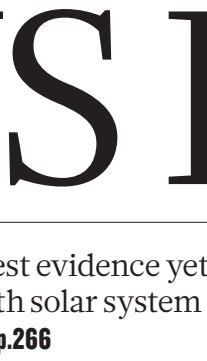

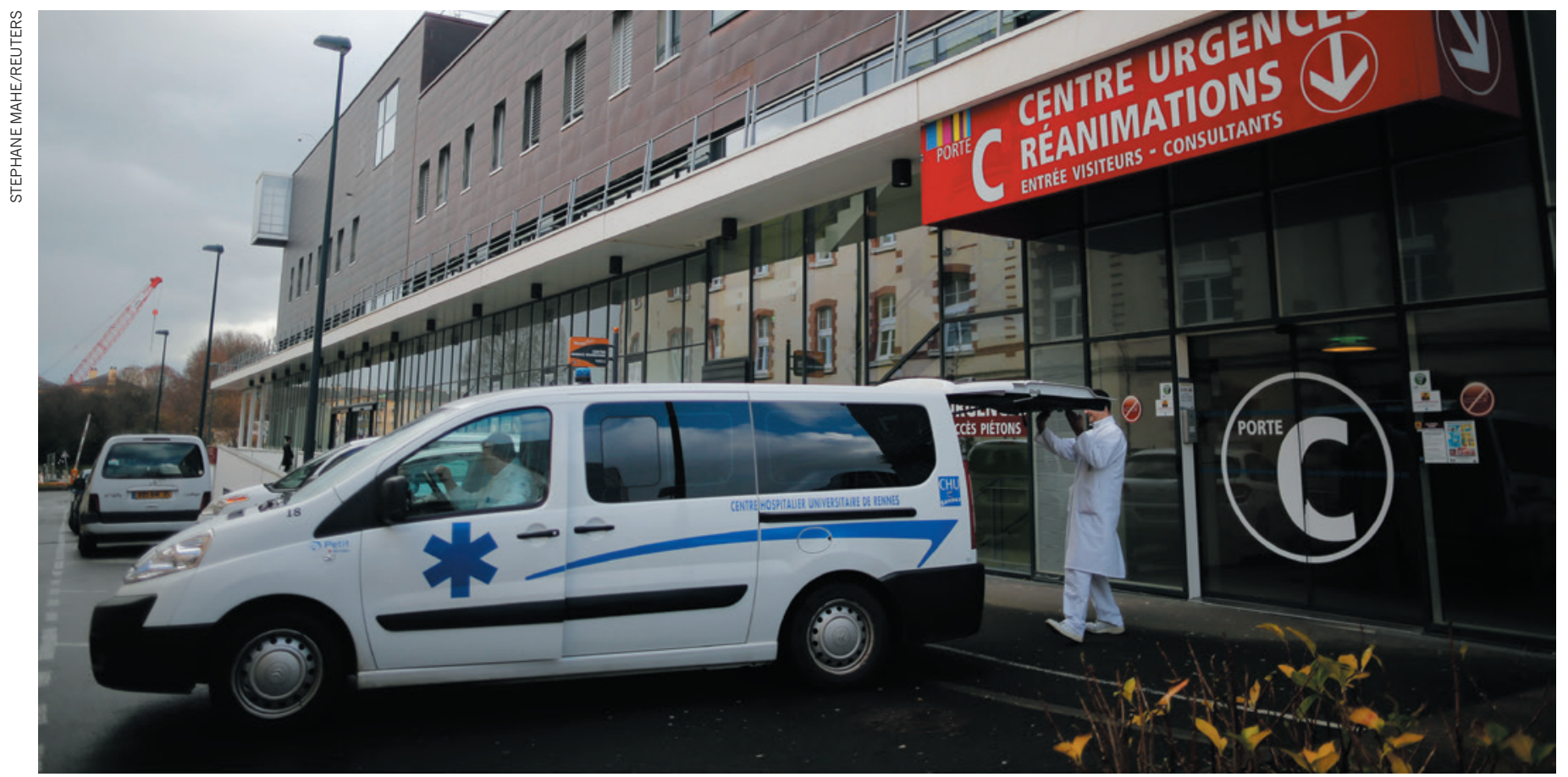

The hospital in Rennes, France, to which six people were taken after suffering adverse effects in a phase I clinical trial.

\title{
Scientists in the dark after fatal French clinical trial
}

\section{Knowledge about the drug's structure would help researchers understand what happened.}

\section{BY DECLAN BUTLER \& EWEN CALLAWAY}

$\mathrm{O}$ ne person died, and five others were hospitalized, after a clinical trial of an experimental drug in France went tragically wrong. But days after the first public acknowledgement of the incidents on 15 January, a lack of official information has left outside experts and the public largely in the dark as to what happened.

"The French authorities have not been very rapid nor transparent in their response," says Catherine Hill, a specialist in clinical-trial design and a former member of the scientific advisory board of France's National Agency for
Medicines and Health Products Safety (ANSM). She adds that French investigations into other medical accidents have often been opaque.

The trial was a 'first-in-human' phase I trial to test the drug's safety in healthy people (see 'Basic facts'). The Portuguese company Bial produced the drug, which was aimed at treating anxiety and motor disorders associated with Parkinson's disease, and chronic pain in people with cancer and other conditions. Biotrial, a French contract-research organization, conducted the trial at its facilities in Rennes.

But many key questions remain unanswered, says Marc Rodwin, a biomedical-law specialist at Suffolk University Law School in Boston,
Massachusetts. This includes how the participants' injuries came about - magneticresonance-imaging scans showed dying and bleeding tissue deep in the brain - and whether the trials were conducted properly.

\section{BRAIN ENZYME}

In particular, neither the French authorities nor Biotrial has disclosed the identity of the molecule administered in the trials. Bial did say that the drug was an FAAH (fatty acid amide hydrolase) inhibitor; FAAH is an enzyme produced in the brain and elsewhere in the body that breaks down neurotransmitters known as endocannabinoids. By 


\section{FATAL DRUG TRIAL}

\section{Basic facts}

- The trial recruited 128 healthy volunteers aged $18-55$, who were paid $€ 1,900$

(US\$2,060) each.

- Ninety people received different doses of the drug, and the remainder a placebo.

- The trial had tested escalating single doses of the drug without observing any serious adverse side effects.

- The six participants who fell ill were the first to receive repeat higher doses over the course of several days.

- The first participant to fall ill experienced

adverse symptoms on 10 January and died on 17 January.

- Biotrial halted the trial on 11 January; the other five affected people were hospitalized in the days that followed.

- One of these patients has since been discharged, and the condition of the other four is judged to be serious but stable. - Authorities are contacting the 84 other people who received the drug at lower doses to arrange medical check-ups; none of the 18 given neurological check-ups over the weekend showed any of the symptoms seen in the hospitalized people. blocking these enzymes, FAAH inhibitors cause endocannabinoids - which activate the same neural receptors as the active chemical in cannabis, and might have painkilling properties - to accumulate in the body.

Some scientists scrambled over the weekend to try to establish the identity of the drug. Among them were Steve Alexander, a molecular pharmacologist at the University of Nottingham Medical School, UK, who has worked on FAAH for 15 years, and his colleague Christopher Southan, a curator for the Guide to Pharmacology database at the University of Edinburgh, UK. Together, the pair examined an online list of drugs in Bial's research pipeline.

The search revealed just two molecules in phase I trials, one of which fitted the therapeutic profile mentioned by Bial, although it was referred to only by a codename, BIA 10-2474. A French newspaper also published a recruitment form given to a volunteer in the trial that mentioned a drug with the same codename. "As best as we can make out, this compound has not been described in the [scientific] literature," says Alexander. "So we're working in the dark."

It is common in the pharmaceutical industry not to reveal the structure of a molecule this early in development - although the practice has been criticized by researchers. "They declare codenames of candidates in development and hide the structure," says Southan. "I think it's time they stopped." That lack of information left researchers trying to guess the structure from published Bial patents over the weekend, Southan adds. He also says that there seems to be no entry for the trial in clinicaltrial registries.

Numerous companies have developed FAAH inhibitors. There is none on the market, because most clinical trials have shown them to be ineffective - but the ones that were previously tested in people proved safe.

\section{OFF-TARGET ACTION}

Many researchers believe that BIA 10-2474 is acting 'off target' - in other words, inhibiting a protein other than an FAAH. To investigate, researchers could radioactively label the compound and test it on brain tissue from cadavers to 'fish out' the proteins it binds to.

Knowing the drug's molecular structure would also enable

scientists to run "Theydeclare computer predic- codenames of tions of this and other candidates in mechanisms that development might result in toxic- and hide the ity. "There's a whole structure." gamut of sophisticated computation analysis to predict anything you like," says Southan.

Other researchers studying the FAAH pathway will probably look more closely at the potential for inhibitors to strike other proteins, Alexander says. "I think it's very likely that both private industry and academic institutions will be looking very hard as to what this off-target affect might be."
The lack of transparency is typical of French investigations, which tend to favour secrecy until firm conclusions are established, says a French health-law specialist who requested anonymity. He notes that the country's rules governing research on human subjects are strong and guarantee substantial protection of trial participants. He adds that safety incidents in clinical trials are almost unheard of in the country, with the price often being delays in the approval of trial applications.

In recent years, there have been two major changes to French laws affecting the approval of drugs in clinical trials. France strengthened its medical-safety laws following the 2009 withdrawal of a diabetes drug that was suspected of causing hundreds of deaths: a 2011 law, in particular, tightened rules on conflicts of interest for people involved in the country's drugapproval process, as well as giving authorities more power to demand safety tests of medications after they are approved. Then, in 2012, the government passed a separate law intended to streamline the rules for research involving humans, to speed up therapeutic progress and to make France a more attractive place for companies to carry out clinical trials.

One possible safety issue in the trial of BIA 10-2474, notes trial-design specialist Hill, is that all six participants seem to have been administered the doses simultaneously, rather than one receiving a test dose and being checked for adverse effects before others were given it.

Simultaneous rather than sequential administration was identified as problematic in a disastrous UK clinical trial in 2006 that caused multiple organ failure in six participants. "From the 2006 catastrophe in London, I had concluded that treating several individuals with the same dose on the same day in a phase I trial was a big mistake," says Hill.

Jean-Marc Gandon, the president and chief executive of Biotrial, says that he cannot immediately respond to queries from Nature, that he is focused on trying to save the patients and that the company will respond later.

Bial spokeswoman Susana Vasconcelos says that the trial had been conducted "in accordance with all the good international practices guidelines, with the completion of tests and preclinical trials" and that the company "is committed to determine thoroughly and exhaustively the causes which are at the origin of this situation".

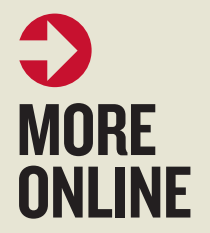

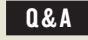

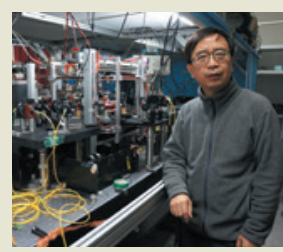

\section{MORE NEWS}

China's quantum space pioneer, Pan Jian-Wei go.nature. $\mathrm{com} / \mathrm{fftxy} 3$ com/2vygzd
- Brightest-ever supernova still baffles astronomers go.nature.

- Seven lessons from the Ebola epidemic go.nature.com/oenddk

- Earliest volcanic-eruption painting in iconic Chauvet cave go.nature.com/w6wgil

\section{NATURE PODCAST}

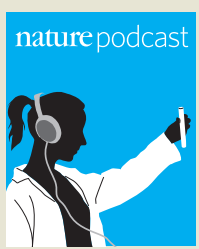

Degradable brain sensors, a 10,000-year-old murder mystery and feral chickens nature.com/nature/ podcast 